\title{
Atenção humanizada ao parto de adolescentes: análise das práticas desenvolvidas em um Centro Obstétrico
}

\author{
Humanized attention to parturition of adolescents: analysis of practices developed in an Obstetric Center
}

Atención humanizada al parto de adolescentes: análisis de las prácticas desarrolladas en un Centro Obstétrico

\section{Josefine Busanello', Nalú Pereira da Costa Kerber", Raúl Andrés Mendoza-Sassi"I, Patrícia de Souza Mano IV , Lulie Rosane Odeh Susin"I", Bruna Goulart Gonçalvesv ${ }^{\vee}$}

' Universidade Federal do Rio Grande, Programa de Pós-Graduação em Enfermagem, Grupo de Pesquisa Viver Mulher. Rio Grande-RS, Brasil.

"Universidade Federal do Rio Grande, Escola de Enfermagem, Grupo de Pesquisa Viver Mulher. Rio Grande-RS, Brasil.

III Universidade Federal do Rio Grande, Faculdade de Medicina, Grupo de Pesquisa Viver Mulher. Rio Grande-RS, Brasil

IV Universidade Federal do Rio Grande, Grupo de Pesquisa Viver Mulher. Rio Grande-RS, Brasil

$\checkmark$ Universidade Federal do Rio Grande, Escola de Enfermagem, Bolsista PIBIC-CNPq-FURG. Rio Grande-RS, Brasil.

Submissão: 18-05-2010 Aprovação: 18-12-2011

\section{RESUMO}

Estudo quantitativo que objetivou analisar as práticas desenvolvidas na assistência à adolescente, a partir do relato dos trabalhadores de um Centro Obstétrico de um Hospital Universitário, com base na proposta de humanização do parto do Ministério da Saúde. Segundo os trabalhadores, estão sendo desenvolvidas práticas úteis na assistência ao parto, dentre as quais as orientações sobre formas de relaxamento no trabalho de parto, o incentivo ao vínculo entre mãe e filho e a amamentação. Porém, o direito ao acompanhante não vem sendo considerado. A posição de litotomia e a padronização da tricotomia, episiotomia e amniotomia foram constatadas. Os registros dos prontuários, dentre eles o partograma, a anamnese, e o exame físico e obstétrico da parturiente mostraram-se insatisfatórios. Conclui-se que, no cenário investigado, são desenvolvidas práticas consideradas adequadas e inadequadas, mostrando a necessidade de incentivar a utilização de procedimentos embasados em evidência científica e inseridos na proposta de humanização do parto.

Descritores: Enfermagem; Parto humanizado; Adolescente; Saúde da mulher.

ABSTRACT
Quantitative study that aimed to analyze the practices developed in assisting the adolescent, from the account of health workers, in an Obstetric Center in a teaching hospital, based on the proposal of humanization of parturition of the Health Ministry. According to the workers, useful practices in assisting parturition, among them, orientations about relaxation techniques at parturition, improving the attachment between mother and child, are being carried out. However, the right to a companion has not been taken into account. The lithotomy position and standardization of trichotomy, episiotomy e amniotomy were registered. Medical records, among them partogram, anamnesis and physical and obstetric exam of the parturient, proved to the unsatisfactory. We conclude that, in the scenario investigated, are developed practices considered appropriate and inappropriate, showing the need to further encourage the use of procedures grounded in scientific evidence and inserted into the proposal to the humanization of birth.

Key words: Nursing; Humanizing delivery; Adolescent; Woman's health.

\section{RESUMEN}

Estudio cuantitativo que buscó analizar las prácticas desarrolladas en la asistencia a la adolescente, del punto de vista de los trabajadores de un Centro Obstétrico de un Hospital Universitario, con base en la propuesta de humanización del parto de Ministerio de la Salud. Las prácticas útiles en la asistencia, entre ellas las orientaciones sobre la manera de relajarse durante el parto, el fomento a las relaciones entre madre e hijo y la lactancia, están sendo desarrolladas. El derecho a escolta no está siendo considerado y la posición de litotomía, la normalización de tricotomía, episiotomía y amniotomía fueran encontradas. El partograma, anamnese y examen físico y obstétrico resultaran insatisfactorios. Llegamos a la conclusión de que se han desarrollado prácticas que se consideran apropiadas y inapropiadas, lo que muestra la necesidad de fomentar aún más el uso de procedimientos basados en las evidencias científicas y inseridos en la humanización del parto.

Palabras clave: Enfermería; Humanización del parto; Adolescente; Salud de la mujer. 


\section{INTRODUÇÃO}

Buscando incluir os princípios de humanização na assistência obstétrica e neonatal, no ano de 2000, o Ministério da Saúde (MS) instituiu o Programa de Humanização do Pré-Natal e Nascimento (PHPN), uma proposta ampla de humanização dos serviços de atenção a todo ciclo gravídico-puerperal. Esse programa apresenta duas características marcantes: o olhar para a integralidade da assistência obstétrica e a afirmação dos direitos da mulher incorporados como diretrizes institucionais ${ }^{(1)}$.

Especificamente, no atendimento ao parto, as ações preconizadas pelo MS estão fundamentadas nas recomendações ao parto normal da Organização Mundial da Saúde (OMS). A partir deste, as práticas desenvolvidas no parto normal são classificadas em quatro categorias: práticas claramente úteis e que devem ser incentivadas; práticas prejudiciais ou ineficazes e que devem ser eliminadas; práticas com evidência insuficiente para apoiar uma recomendação e que deveriam ser usadas com precaução; práticas frequentemente utilizadas de forma inapropriada, provocando mais dano que benefício.

Assim, com base na proposta de humanização, o desenvolvimento dessas práticas na assistência à parturição prevê atitudes e comportamentos dos trabalhadores da saúde que contribuam para reforçar o caráter de atenção à saúde como um direito de todas as mulheres. Entretanto, na realidade de muitos serviços de saúde, muitas dessas recomendações ainda não foram introduzidas, ou encontram resistências para sua efetivação nos Centros Obstétricos $(\mathrm{COs})^{(2)}$.

Considerando as especificidades da mulher adolescente, os estudos voltados para atenção ao parto nessa faixa etária, em sua maioria, estão direcionados aos problemas biopsicossociais que podem advir da maternidade precoce, e aos riscos obstétricos e neonatais do ciclo gravídico-puerperal ${ }^{(3)}$. Apesar das particularidades fisiológicas e emocionais que acompanham o período da adolescência e influenciam o transcurso da gravidez e do parto nessa faixa etária, a assistência ao parto de adolescentes, na perspectiva da humanização, é pouco abordada nos estudos. Essa lacuna do conhecimento precisa ser transposta em virtude do cenário atual em que se apresentam os serviços de atenção à saúde, que recebem um grande número de adolescentes grávidas ${ }^{(1)}$.

Nessa perspectiva, justifica-se a relevância do presente estudo, que está voltado para a atuação dos trabalhadores da saúde e sua participação na efetivação da atenção humanizada ao parto de adolescentes, considerando que esses são importantes mediadores de tal proposta. A implementação do PHPN requer o envolvimento e a aderência dos trabalhadores da saúde, mediante a compreensão de que a forma como é assistido e vivenciado esse processo, pode ser decisiva para a promoção de uma maternidade segura, especialmente para a parturiente adolescente.

$\mathrm{Na}$ tentativa de contribuir para a humanização da atenção ao parto de adolescentes, este estudo tem como objetivo analisar as práticas desenvolvidas na assistência à parturiente adolescente, a partir do relato dos trabalhadores da saúde e da pesquisa documental dos registros existentes, em um CO, de um Hospital Universitário (HU), com base na proposta de humanização do parto preconizada pelo MS.

\section{METODOLOGIA}

Este estudo, de abordagem quantitativa, é um recorte do banco de dados da macropesquisa multicêntrica intitulada: "Atenção humanizada ao parto de adolescentes". Os dados utilizados foram coletados a partir de duas fontes: a) entrevistas semiestruturadas, bem como perguntas abertas, realizadas com os 23 trabalhadores da saúde efetivos, no período de julho de 2008 a fevereiro de 2009, em um CO, de um $\mathrm{HU}$, do sul do Brasil; b) pesquisa documental no prontuário de adolescentes internadas em trabalho de parto neste CO, pelo Sistema Único de Saúde (SUS), no mesmo período considerado para os trabalhadores da saúde, totalizando 128 prontuários.

Os instrumentos de coleta de dados para a entrevista semiestruturada e a pesquisa documental contiveram questões embasadas nas recomendações para o parto normal da OMS, contidas no PHPN ${ }^{(1)}$, ou seja, práticas claramente úteis e que devem ser encorajadas na assistência ao parto normal; práticas claramente prejudiciais ou ineficazes e que devem ser eliminadas na assistência ao parto normal; e práticas frequentemente utilizadas de modo inadequado na assistência ao parto normal.

As entrevistas com os trabalhadores da saúde foram realizadas no próprio $\mathrm{CO}$, durante os turnos de trabalho, em momento acordado previamente e sem relação com os partos. Foram conduzidas em um período de trinta minutos a uma hora, gravadas e, posteriormente, transcritas. A pesquisa documental nos prontuários foi realizada na Unidade de Internação Obstétrica, durante o período de internação das adolescentes. Os entrevistadores foram alunos da Graduação de Enfermagem, previamente orientados.

A macropesquisa, à qual o presente estudo está vinculado, obteve a aprovação do Comitê de Ética em Pesquisa, da Universidade Federal do Rio Grande (CEPAS), sob o No 31/2008. As entrevistas com os sujeitos foram realizadas após a assinatura do consentimento livre e esclarecido.

Os dados coletados foram revisados e duplamente digitados em ordem inversa por diferentes digitadores; posteriormente, comparados e corrigidos. Todas essas etapas foram realizadas utilizando-se o programa Epi-Info 6.04, sendo que os dados foram analisados através do pacote estatístico Stata 9.2. Diferenças entre proporções foram testadas pelo teste do Qui quadrado ou pelo teste exato de Fisher, adotando o valor de $p<0,05$ de um teste bicaudal. Os temas elencados foram discutidos e analisados, estabelecendo uma correlação com as orientações do MS acerca da proposta de parto humanizado.

\section{RESULTADOS}

Os dados estão apresentados na forma de tabelas, divididas de acordo com a primeira, segunda e quarta categorias das práticas recomendadas pela OMS, contidas no PHPN(1), na assistência ao parto normal. Primeiramente, é realizada a 
Tabela 1 - Práticas desenvolvidas na assistência ao parto de adolescentes em CO de um HU, Rio Grande do Sul, Brasil, julho de 2008 a fevereiro de 2009.

\begin{tabular}{|c|c|c|c|c|c|c|}
\hline & $\begin{array}{c}\text { Enfermeiros } \\
\mathrm{n}(4)\end{array}$ & $\begin{array}{c}\text { Téc./Aux. } \\
\text { Enfermagem } \\
\mathbf{n}(6) \\
\end{array}$ & $\begin{array}{c}\text { Médicos Precep- } \\
\text { tores } \\
\mathbf{n}(6)\end{array}$ & $\begin{array}{c}\text { Médicos Resi- } \\
\text { dentes } \\
n(7) \\
\end{array}$ & $\begin{array}{l}\text { TOTAL } \\
\text { N (23) }\end{array}$ & p-Valor \\
\hline \multicolumn{7}{|c|}{ I. Práticas claramente úteis e que devem ser encorajadas na assistência ao parto normal } \\
\hline \multicolumn{7}{|c|}{ Respeito à privacidade e intimidade } \\
\hline Sim & $75,0 \%$ & $66,7 \%$ & $50,0 \%$ & $85,7 \%$ & $69,6 \%$ & 0,9 \\
\hline Não & $25,0 \%$ & $33,3 \%$ & $50,0 \%$ & $14,3 \%$ & $30,4 \%$ & \\
\hline \multicolumn{7}{|c|}{ Relação da equipe com a parturiente e familiares } \\
\hline Muito boa/boa & $75,0 \%$ & $66,7 \%$ & $83,3 \%$ & $100,0 \%$ & $82,6 \%$ & 0,415 \\
\hline Regular/Ruim & $25,0 \%$ & $33,3 \%$ & $16,7 \%$ & $0,0 \%$ & $17,4 \%$ & \\
\hline \multicolumn{7}{|c|}{ Medidas de higiene } \\
\hline Sim & $100,0 \%$ & $83,3 \%$ & $66,7 \%$ & $100,0 \%$ & $87,0 \%$ & 0,326 \\
\hline Não/As vezes & $0,0 \%$ & $16,7 \%$ & $33,3 \%$ & $0,0 \%$ & $13,0 \%$ & \\
\hline \multicolumn{7}{|c|}{ Orientações sobre relaxamento } \\
\hline Sim & $100,0 \%$ & $83,3 \%$ & $66,7 \%$ & $85,7 \%$ & $82,6 \%$ & 0,801 \\
\hline Não & $0,0 \%$ & $16,7 \%$ & $33,3 \%$ & $14,3 \%$ & $17,4 \%$ & \\
\hline \multicolumn{7}{|c|}{ Orientações sobre o parto } \\
\hline Sim & $75,0 \%$ & $100,0 \%$ & $83,3 \%$ & $100,0 \%$ & $91,3 \%$ & 0,415 \\
\hline Não/As vezes & $25,0 \%$ & $0,0 \%$ & $16,7 \%$ & $0,0 \%$ & $8,7 \%$ & \\
\hline \multicolumn{7}{|c|}{ Contato precoce mãe e recém-nascido } \\
\hline Sim & $100,0 \%$ & $83,3 \%$ & $83,3 \%$ & $100,0 \%$ & $91,3 \%$ & 0,668 \\
\hline Não & $0,0 \%$ & $16,7 \%$ & $16,7 \%$ & $0,0 \%$ & $8,7 \%$ & \\
\hline \multicolumn{7}{|c|}{ Incentivo amamentação no CO } \\
\hline Sim & $100,0 \%$ & $100,0 \%$ & $83,3 \%$ & $100,0 \%$ & $95,6 \%$ & 0,696 \\
\hline Não & $0,0 \%$ & $0,0 \%$ & $16,7 \%$ & $0,0 \%$ & $4,4 \%$ & \\
\hline \multicolumn{7}{|c|}{ Tempo entre nascimento e primeira mamada } \\
\hline Até $30 \mathrm{~min}$. & $50,0 \%$ & $33,3 \%$ & $33,3 \%$ & $71,4 \%$ & $47,8 \%$ & 0,458 \\
\hline Após 30 min. & $50,0 \%$ & $66,7 \%$ & $66,7 \%$ & $28,6 \%$ & $52,2 \%$ & \\
\hline \multicolumn{7}{|c|}{ Envolvimento na escolha do tipo de parto } \\
\hline Sim & $0,0 \%$ & $33,3 \%$ & $0,0 \%$ & $14,3 \%$ & $13,0 \%$ & 0,715 \\
\hline Não & $100,0 \%$ & $66,7 \%$ & $100,0 \%$ & $85,7 \%$ & $87,0 \%$ & \\
\hline \multicolumn{7}{|c|}{ Presença do acompanhante } \\
\hline Sim & $75,0 \%$ & $0,0 \%$ & $16,7 \%$ & $0,0 \%$ & $17,4 \%$ & 0,009 \\
\hline Não & $25,0 \%$ & $100,0 \%$ & $83,83 \%$ & $100,0 \%$ & $82,6 \%$ & \\
\hline \multicolumn{7}{|c|}{ II. Práticas claramente prejudiciais ou ineficazes e que devem ser eliminadas na assistência ao parto normal } \\
\hline \multicolumn{7}{|c|}{ Posição rotineira do parto } \\
\hline Litotomia & $100,0 \%$ & $100,0 \%$ & $100,0 \%$ & $85,7 \%$ & $95,6 \%$ & 1,0 \\
\hline Outras & $0,0 \%$ & $0,0 \%$ & $0,0 \%$ & $14,3 \%$ & $4,4 \%$ & \\
\hline \multicolumn{7}{|c|}{ Tricotomia de rotina } \\
\hline Sim & $75,0 \%$ & $66,7 \%$ & $50,0 \%$ & $85,7 \%$ & $69,6 \%$ & 0,607 \\
\hline Não & $25,0 \%$ & $33,3 \%$ & $50,0 \%$ & $14,3 \%$ & $30,4 \%$ & \\
\hline \multicolumn{7}{|c|}{ Enteroclisma de rotina } \\
\hline Sim & $0,0 \%$ & $0,0 \%$ & $0,0 \%$ & $14,3 \%$ & $4,3 \%$ & 1,0 \\
\hline Não & $100,0 \%$ & $100,0 \%$ & $100,0 \%$ & $85,7 \%$ & $95,7 \%$ & \\
\hline \multicolumn{7}{|c|}{ Episiotomia de rotina } \\
\hline Sim & $100,0 \%$ & $100,0 \%$ & $66,7 \%$ & $57,1 \%$ & $78,3 \%$ & 0,170 \\
\hline Não & $0,0 \%$ & $0,0 \%$ & $33,3 \%$ & $42,9 \%$ & $21,7 \%$ & \\
\hline \multicolumn{7}{|c|}{ III. Práticas frequentemente utilizadas de modo inadequado na assistência ao parto normal } \\
\hline \multicolumn{7}{|c|}{ Jejum } \\
\hline Sim & $25,0 \%$ & $16,7 \%$ & $33,3 \%$ & $14,3 \%$ & $21,7 \%$ & 0,682 \\
\hline Não & $75,0 \%$ & $83,3 \%$ & $66,7 \%$ & $85,7 \%$ & $78,3 \%$ & \\
\hline Amniotomia de & & & & & & \\
\hline Sim & $75,0 \%$ & $66,7 \%$ & $50,0 \%$ & $100,0 \%$ & $73,9 \%$ & 0,171 \\
\hline Não & $25,0 \%$ & $33,3 \%$ & $50,0 \%$ & $0,0 \%$ & $26,1 \%$ & \\
\hline Infusão de ocit & & & & & & \\
\hline Sim & $100,0 \%$ & $100,0 \%$ & $100,0 \%$ & $71,4 \%$ & $91,3 \%$ & 0,225 \\
\hline Não & $0,0 \%$ & $0,0 \%$ & $0,0 \%$ & $28,6 \%$ & $8,7 \%$ & \\
\hline
\end{tabular}

Fonte: Entrevistas semiestruturadas com trabalhadores da saúde de um CO de um HU, Rio Grande do Sul, Brasil. 
descrição dos dados disponibilizados na Tabela 1, que retrata os achados obtidos a partir das entrevistas semiestruturadas com os trabalhadores da saúde.

De acordo com a Tabela 1, é possível visualizar que práticas claramente úteis e que devem ser realizadas na assistência ao parto normal estão sendo implementadas no $\mathrm{CO}$ em estudo, e que não existem diferenças estatisticamente significativas entre as categorias, com exceção da presença de acompanhante.

Os trabalhadores consideram que a privacidade e intimidade das parturientes são respeitadas. Todavia, quando dissertam acerca disso ressaltam fatores que podem interferir no desenvolvimento dessa prática, dentre eles: a estrutura física inadequada do CO; o despreparo dos acadêmicos; e a falta de postura dos trabalhadores da saúde acerca das particularidades de cada parturiente.

A relação da equipe com as parturientes e os familiares, segundo a maioria dos trabalhadores, é considera muito boa e boa (Tabela 1). No entanto, ao analisar as respostas dos entrevistados sobre as dificuldades que interferem nessa relação, destacaram-se: a falta de preparo e conhecimento das parturientes e dos familiares para o enfrentamento do processo de parturição, que deve ser promovida durante o pré-natal; e a falta de sensibilidade dos próprios trabalhadores.

Ainda na Tabela 1, visualiza-se que, mais de dois terços dos trabalhadores, consideram que as medidas de higiene são desenvolvidas na assistência à parturiente. Segundo os trabaIhadores, além de receberem orientações acerca do parto e da forma como podem se ajudar neste momento, as parturientes recebem orientações sobre as formas de relaxamentos durante o trabalho de parto, sendo elas: técnicas de respiração; o banho morno; a deambulação; e massagem lombar.

No tocante à prática do aleitamento materno apresentada na Tabela 1, o contato precoce e a amamentação, para a maioria dos trabalhadores, são incentivados. O intervalo de tempo entre o nascimento e a mamada é predominante entre meia e uma hora pós-parto.

Também podemos observar que algumas práticas úteis não estão sendo desenvolvidas. Sobre a escolha do tipo de parto, os trabalhadores afirmaram que não há o envolvimento das parturientes nesse processo decisório. $\mathrm{O}$ direito à presença de um acompanhante de escolha da parturiente durante o trabalho de parto e parto, segundo o relato dos trabalhadores, não é respeitado. Em relação a esta variável, foi encontrada diferença significativa na forma de visualização entre as categorias funcionais. Diferentemente das demais categorias funcionais, três quartos dos enfermeiros referiram que esse direito das parturientes não é preservado.

Algumas práticas prejudiciais e que, segundo a OMS, devem ser eliminadas da assistência à parturição, são desenvolvidas no $\mathrm{CO}$ investigado, de acordo com a Tabela 1, sendo elas a padronização da tricotomia, da episiotomia e da utilização da posição de litotomia para o parto.

Segundo os trabalhadores, a tricotomia é considerada uma prática rotineira, sendo que a sua realização depende do médico de plantão, e as justificativas surgidas para a sua padronização na análise qualitativa são: facilitar a higiene da parturiente; favorecer o desenvolvimento de alguns procedimentos, tais como a episiotomia e as manobras no momento do parto; e diminuir os riscos de infecção e de má cicatrização da episiorrafia. Contraditoriamente, outros trabalhadores ressaltaram a inexistência de comprovações científicas acerca das vantagens deste procedimento.

A padronização da episiotomia, segundo os trabalhadores, está atrelada à preocupação com a primiparidade das parturientes, e à prevenção de lacerações. Isto ficou evidente na análise dos relatos dos trabalhadores da saúde, onde se observou que na maioria das vezes, as parturientes nem são informadas sobre a realização deste procedimento e, por isso, não expressam nenhuma opinião sobre o mesmo.

Outra prática danosa, apresentada na Tabela 1, diz respeito à prática do enteroclisma, que segundo a maioria dos trabaIhadores, não é considerada rotineira no $\mathrm{CO}$ em estudo. Os trabalhadores ressaltam que essa conduta é contraindicada na literatura, por não trazer benefícios para a parturiente e para o bebê. A minoria dos trabalhadores que afirma executar tal prática justifica que, o enteroclisma pode ter um papel importante no processo de acelerar o parto e o esvaziamento intestinal nos casos em que a parturiente se apresentar constipação.

No que se refere às práticas frequentemente utilizadas de modo inadequado na assistência ao parto normal, apresentadas na Tabela 1, aproximadamente oito em cada dez dos trabalhadores da saúde desconsidera o favorecimento da alimentação e ingestão de líquidos durante a permanência das parturientes no CO. Em relação à infusão venosa com ocitócito e a realização da amniotomia, os trabalhadores afirmam que estas práticas são utilizadas de forma rotineira no $\mathrm{CO}$ em estudo.

Na Tabela 2, apresentam-se os dados coletados a partir da pesquisa documental realizada nos prontuários das adolescentes. Observa-se que algumas práticas comprovadamente úteis e que devem ser estimuladas na assistência ao parto não estão sendo desenvolvidas no $\mathrm{CO}$ em estudo. Uma dessas práticas é o registro adequado das informações e condutas adotadas durante o trabalho de parto e parto. Nenhum dos prontuários analisados apresentou registros completos dos dados pesquisados: a utilização do partograma foi evidenciada em apenas um terço dos prontuários analisados; oito de cada dez prontuários não apresentavam anamnese completa; as informações referentes ao exame físico geral e obstétrico constavam em apenas três de cada dez prontuários; e a vigilância fetal, presente em menos de $60 \%$ dos prontuários.

Dentre as práticas que podem prejudicar a parturiente, de acordo com a Tabela 2, prevalece uma incidência elevada da utilização rotineira da episiotomia. A utilização de dispositivos invasivos, tais como fórceps, sondas vesicais e cateterização profilática de rotina, foi evidenciada em poucos dos prontuários analisados, sendo que este fato pode estar atrelado à falta de registro dessa prática.

A infusão de ocitocina também foi investigada nos prontuários das adolescentes, sendo que em mais de $80 \%$ dos prontuários analisados não havia o registro desta informação. Em 13\% dos prontuários foi encontrado o registro da administração de ocitócito durante o trabalho de parto. A analgesia peridural no parto normal, de acordo com a Tabela 2, foi realizada em $18,7 \%$ das parturientes. 
Tabela 2 - Práticas desenvolvidas na assistência ao parto de adolescentes em CO de um HU, Rio Grande do Sul, Brasil, julho de 2008 a fevereiro de 2009.

PRONTUARIOS n(128) \%

\section{Práticas claramente úteis e que devem ser} encorajadas na assistência ao parto normal

\begin{tabular}{lc}
\hline Registros nos Prontuários & $0,0 \%$ \\
Completo & $100,0 \%$ \\
Incompleto & \\
\hline Numero de consultas no pré-natal & $3,1 \%$ \\
Nenhuma & $22,7 \%$ \\
Ate seis & $71,1 \%$ \\
Sete ou mais & $3,1 \%$ \\
Não registrado no prontuário & \\
\hline Utilização do partograma & $29,7 \%$ \\
Sim & $79,3 \%$ \\
Não registrado no prontuário & \\
\hline Vigilância fetal & $58,6 \%$ \\
Sim & $41,4 \%$ \\
Não registrado no prontuário & \\
\hline Anamnese & $11,7 \%$ \\
Completa & $6,3 \%$ \\
Incompleta & $82,0 \%$ \\
\hline Não registrado no prontuário & $32,0 \%$ \\
\hline Exame físico geral e obstétrico & $68,0 \%$ \\
\hline Não registrado no prontuário &
\end{tabular}

II. Práticas claramente prejudiciais ou ineficazes e que devem ser eliminadas na assistência ao parto normal

\begin{tabular}{ll}
\hline Episiotomia & \\
Sim & $46,1 \%$ \\
Não & $24,2 \%$ \\
Não registrado no prontuário & $29,7 \%$ \\
\hline Dispositivos invasivos & \\
Sim & $10,9 \%$ \\
Não & $24,3 \%$ \\
Não registrado no prontuário & $64,8 \%$ \\
\hline
\end{tabular}

III. Práticas frequentemente utilizadas de modo inadequado na assistência ao parto normal

\begin{tabular}{lc}
\hline Analgesia no parto & \\
Sim & $18,7 \%$ \\
Não & $81,3 \%$ \\
\hline Ocitocina & \\
Sim & $13,3 \%$ \\
Não & $3,1 \%$ \\
Não registrado no prontuário & $83,6 \%$ \\
\hline
\end{tabular}

Fonte: Prontuários do CO de um HU, Rio Grande do Sul, Brasil
Destaca-se também na Tabela 2, o número significativo de adolescentes que realizaram o acompanhamento da gestação $(97 \%)$, sendo que $71 \%$ das adolescentes realizaram mais de sete consultas pré-natais.

\section{DISCUSSÃO}

O respeito à privacidade da parturiente é uma das práticas preconizadas pela proposta de humanização do parto. No entanto, a inadequação física da unidade de atendimento ao parto, é apontada pelos trabalhadores e em outros estudos ${ }^{(2,4)}$, como um dos aspectos que dificulta a preservação da intimidade da parturiente e assistência de qualidade.

A estrutura adequada do CO é uma condição indispensável para que seja desenvolvida uma assistência humanizada, voltada para o respeito à integridade da mulher. Nesta perspectiva, o MS recomenda a organização das unidades obstétricas em quartos PPP, caracterizados por leitos individuais, com banheiro anexo, destinados à assistência da mulher durante o trabalho de parto, parto e pós-parto imediato ${ }^{(5)}$.

O despreparo dos acadêmicos e a falta de postura dos trabalhadores da saúde acerca das particularidades de cada parturiente, de igual forma são fatores que ferem a privacidade e a intimidade das adolescentes. Entende-se que o processo de parturição faz com que a exposição e a intrusão alheia no corpo da mulher sejam fatos normais e aceitáveis. Um estudo desenvolvido com parturientes adolescentes em Minas Gerais evidenciou que os trabalhadores da saúde manipulam a parturiente como um ser assexuado, sem sentimentos, subserviente e alheio às condições circundantes, como a vergonha ou a dor. Essa falta de respeito à parturiente, em especial, à mulher adolescente, pode fomentar representações negativas acerca do processo de parturição, que futuramente poderão repercutir no desenrolar da maternidade ${ }^{(6)}$.

A relação entre os trabalhadores e as parturientes e familiares, foi considerada boa pelos trabalhadores, diferentemente de outras realidades, nas quais a relação é, muitas vezes, marcada pela desconfiança, desrespeito e conflito. A existência de relações assimétricas está representada pelo desconhecimento das mulheres acerca dos acontecimentos relacionados ao processo parturitivo e dos seus direitos, uma vez que a elas vem sendo negado tradicionalmente o acesso a estas informações ${ }^{(7)}$

$\mathrm{O}$ aspecto referente à falta de preparo e conhecimento das parturientes e dos familiares para o enfrentamento do processo de parturição foi ressaltado pelos trabalhadores, como prejudicial para a relação com as parturientes e familiares. Esta afirmação parece contraditória ao se analisar o número de adolescentes que realizaram o acompanhamento da gestação, e que, portanto, deveriam ter sido preparadas neste momento. $\mathrm{O}$ estudo mostrou índice satisfatório de adesão das adolescentes ao serviço de pré-natal, de acordo com o MS que preconiza um mínimo de seis consultas durante o período gestacional ${ }^{(1)}$, o que mostra a necessidade de outros estudos que avaliem a qualidade do pré-natal que vem sendo realizado.

Um número elevado de gestantes adolescentes não segue o calendário mínimo recomendado. A falta de adesão das 
adolescentes aos serviços pré-natais está atrelada, principalmente, à dificuldade de aceitação da gravidez, de apoio familiar e de acesso aos serviços destinados a esse atendimento ${ }^{(3)}$.

Em relação às medidas de higiene, se mostra como um índice satisfatório, já que uma das principais finalidades do processo de humanização do parto e nascimento é o conforto da parturiente. Durante o trabalho de parto, pela excessiva secreção vaginal e sudorese, a higiene da parturiente deve ser estimulada, favorecendo o seu bem estar ${ }^{(1)}$.

As formas de relaxamentos durante o trabalho de parto, referidas como sendo desenvolvidas pelos trabalhadores, tais como técnicas de respiração, banho morno, deambulação e massagem lombar, são amplamente recomendadas pela OMS. O uso de métodos não farmacológicos de alívio da dor, além de proporcionar conforto à parturiente, evita que o processo fisiológico do parto seja influenciado por substâncias farmacológicas ${ }^{(1)}$. Um estudo realizado com adolescentes em uma maternidade de Belo Horizonte revelou os benefícios na massagem para estas parturientes, fazendo com que a sensação de dor durante as contrações fosse diminuída(6). A deambulação e as técnicas de respiração auxiliam no alívio da dor durante o trabalho de parto, além de tornar as contrações uterinas mais intensas e eficientes para a dilatação cervical ${ }^{(1)}$. A massagem lombar, não apenas como um ato mecânico e físico das mãos, mas como a concretização de um cuidar mais abrangente, pode favorecer a diminuição da dor e das tensões da parturiente ${ }^{(6)}$.

As orientações realizadas acerca do parto, conforme o relato dos trabalhadores, configuram-se como uma prática relevante na atenção à parturição, já que o ciclo gravídico-puerperal pode trazer dúvidas, inseguranças e medos, principalmente para as adolescentes. A qualidade do acolhimento e do cuidado prestado à adolescente, que procura a assistência à parturição, pode ser determinante no desenrolar desse processo. Para tanto, as práticas de atenção deverão nortear-se pelo princípio da humanização, enfatizando que as ações dos trabalhadores da saúde devem contribuir para reforçar o caráter da atenção focado nos direitos da parturiente. Neste sentido, a finalidade da assistência prestada é melhorar o grau de informação das mulheres em relação ao seu corpo, suas condições de saúde, além de ampliar sua capacidade de fazer escolhas adequadas ao seu contexto e momento de vida ${ }^{(1)}$.

Segundo estudo realizado em uma maternidade do Rio de Janeiro, as informações recebidas pelas mulheres durante o trabalho de parto e parto apresentaram uma clara associação com a satisfação em relação à assistência, ou seja, quanto mais completa e suficiente a orientação foi percebida pela parturiente, maior a satisfação em relação à assistência à parturição. Ademais, o grau de informação pode aumentar a percepção da mulher sobre o evoluir do parto e favorecer a sua participação nas decisões e escolhas sobre as condutas adotadas neste momento ${ }^{(8)}$.

No tocante à prática de incentivo ao contato precoce e à amamentação e tempo entre o nascimento e a mamada, revelam-se como dados que coadunam com as recomendações do MS, que preconiza o contato da mãe com seu bebê e aleitamento materno na sala de parto ${ }^{(1)}$. O recém-nascido em posição prona sobre o peito da mãe, imediatamente após o parto, proporciona um ambiente ótimo para sua adaptação à vida extrauterina e para a adaptação da mulher à maternidade. A equipe de saúde possui um papel importante nesse momento da assistência. As orientações e o incentivo ao contato precoce podem favorecer o vínculo entre mãe e filho, além de serem consideradas ações que potencializam o mecanismo para a promoção do aleitamento materno ${ }^{(9)}$.

Segundo o MS, o predomínio do parto cesáreo está atrelado a diversos determinantes, com destaque para a situação de submissão e aceitação à qual as parturientes são submetidas. As mulheres têm dificuldade de participar da decisão do tipo de parto e sentem-se menos capacitadas para efetuar escolhas frente às "questões técnicas"(1).

No que se refere à presença de um acompanhante de escolha da parturiente durante o trabalho de parto e parto, evidenciou-se neste estudo, assim como em outros desenvolvidos nesta área, como um direito da mulher que não vem sendo respeitado pelos trabalhadores. Este dado demonstra certa fragilidade na assistência prestada, pois um dos aspectos mais evocados pelo ideário de humanização da atenção do parto proposto pelo MS é a participação e o envolvimento da família neste processo ${ }^{(1)}$.

Além disso, ao se considerar a especificidade das parturientes adolescentes, o direito à presença do acompanhante está assegurado por legislação específica. No Estatuto da Criança e Adolescente (ECA), embora não estejam previstos tópicos especiais sobre a saúde reprodutiva dos adolescentes, a lei assegura o direito a acompanhante, identificado como responsável legal, durante a assistência ao ciclo gravídico puerperal $^{(10)}$.

Ainda em relação ao direito do acompanhante, os enfermeiros se mostraram mais convencidos da importância desta prática no processo de parturição. Achado que pode estar relacionado à expressiva participação dos enfermeiros na efetivação da proposta de humanização do parto. A Enfermagem tem desenvolvido estudos e pesquisas acerca da saúde da muIher, em defesa do PHPN e da implementação das práticas preconizadas por este programa. Neste sentido, o enfermeiro tem sido reconhecido pelo MS como o profissional que possui formação holística e procura atuar de forma humanizada no cuidado à parturiente ${ }^{(1)}$. É possível que este trabalhador esteja mais empenhado na efetivação do PHPN.

No que se refere a padronização da tricotomia, muitos estudos também evidenciaram altos índices dessa prática entre pacientes atendidas em hospitais públicos do Brasil(11,12). Não existem evidências claras sobre esses benefícios. Ao contrário, a tricotomia causa desconforto no momento da sua execução e favorece o risco de transmissão de doenças, quando realizada sem a utilização de lâminas descartáveis. Por estas razões, é recomendado que a tricotomia só seja feita se esta for opção da parturiente ${ }^{(12)}$.

Assim como achados do presente estudo, na realidade nacional, de todos os procedimentos associados ao nascimento, a episiotomia representa índices elevados, sendo realizada em mais de $90 \%$ dos partos vaginais ${ }^{(13)}$. Conforme a OMS, o uso rotineiro e liberal da episiotomia é considerado uma prática 
prejudicial e ineficaz, sendo indicada somente em cerca de $10 \%$ a $15 \%$ dos casos. Como um procedimento cirúrgico, a incisão perineal para ampliação do canal do parto envolve riscos, dentre eles, extensão da lesão, hemorragia significativa, dor no pós-parto, edema, infecções, hematoma, dispareunia, fístulas retovaginais e, embora raro, a endometriose da episiorrafia ${ }^{(14)}$.

Uma revisão sistemática, publicada pela biblioteca Cochrane, concluiu que a episiotomia seletiva, se comparada à rotineira, em todos os partos vaginais, associou-se a menor risco de trauma de períneo posterior, a menor necessidade de sutura e a menos complicações na cicatrização. A utilização seletiva desta prática traz maiores benefícios que a rotineira, sendo indicadas somente em casos de sofrimento fetal, de feto em apresentação pélvica, de progressão insuficiente do parto e de ameaça de laceração perineal de terceiro grau ${ }^{(15)}$.

Os trabalhadores da saúde relatam que, na maioria das vezes, as parturientes nem são informadas sobre a realização deste procedimento e, por isso, não expressam nenhuma opinião sobre o mesmo. A exclusão das parturientes acerca das decisões obstétricas, também foi evidenciada em estudos realizados em Minas Gerais(14) e Santa Catarina ${ }^{(16)}$. A maioria das parturientes não recebeu qualquer tipo de informação em relação à episiotomia, sendo que esta intervenção foi realizada sem sua autorização prévia ${ }^{(14)}$. O desconhecimento das mulheres em relação à episiotomia e ao seu próprio corpo, reforça o poder dos trabalhadores da saúde e a exclusão da parturiente do ato decisório. A imposição autoritária e não informada de práticas obstétricas revela a violação dos direitos da mulher no processo decisório e da sua integridade corporal ${ }^{(16)}$.

A predominância da posição de litotomia, revelada pelos trabalhadores, é um aspecto que não coaduna com as recomendações do $\mathrm{MS}^{(1)}$. É recomendado que as parturientes sejam estimuladas a adotar posições não supinas durante $\mathrm{o}$ trabalho de parto e parto, pois estas estão associadas à redução do tempo do segundo período do parto, redução da necessidade de partos assistidos, de episiotomias, da sensação dolorosa na fase expulsiva e das alterações da frequência cardíaca fetal ${ }^{(17)}$.

Um estudo realizado em uma maternidade pública no município do Rio de Janeiro evidenciou os benefícios da escolha da posição vertical para o parto. Além de favorecer o escore de Apgar superior a sete, no primeiro e quinto minutos, a utilização de posições não supinas diminuiu os índices de episiotomia, sendo que as lacerações perineais, quando ocorreram, foram, em sua maioria, de primeiro grau ${ }^{(13)}$.

Outra prática considerada prejudicial pelo MS é o uso rotineiro de enteroclisma, que no presente estudo foi revelada como uma prática pouco desenvolvida. Uma investigação que visou analisar os efeitos do uso de enteroclisma durante o trabalho de parto e parto evidenciou que seu uso não abreviou o tempo de trabalho de parto e nem diminuiu a contaminação fecal. Algumas mulheres possuem receio em evacuar na sala de parto, submetendo-se ao procedimento mesmo que este Ihe traga incômodo. Contudo, na opinião de outras parturientes, o enema foi considerado desconfortável e constrangedor, julgando-o desnecessário. Nesta perspectiva, é imprescindível avaliação do uso do esvaziamento intestinal de rotina, analisando-se caso a caso, respeitando a opinião e a vontade da mulher, e indicando-o apenas quando houver ampola retal cheia, constatada pelo toque vaginal(18).

Uma das práticas que são utilizadas de modo inadequado na assistência ao parto normal e, de acordo com os trabalhadores deste estudo, amplamente realizada, é o jejum de rotina para as parturientes. $\mathrm{O}$ trabalho de parto pode levar, em média, treze horas para as primíparas e oito horas para as multíparas, o faz com que o gasto de energia seja elevado, trazendo possíveis desconfortos para a parturiente e riscos para o feto, pela redução dos níveis de glicemia. Por isso, a oferta hídrica e alimentar deve ser avaliada, de acordo com as condições e a evolução do trabalho de parto, sendo recomendada às gestantes de baixo risco, durante a fase ativa do trabalho de parto ${ }^{(1)}$.

Em relação à infusão venosa com ocitócito, observou-se, tanto a partir dos relatos dos trabalhadores, como nos registros nos prontuários, a utilização dessa medicação. No entanto, é importante ressaltar que não foi explicitada a relação desta prática com o período do trabalho de parto. O ocitócito, quando utilizado durante a fase ativa do trabalho de parto, caracteriza-se como um manejo ativo, considerado pela MS como uma prática prejudicial. A utilização desse fármaco durante o terceiro estágio do parto é recomendada como uma prática benéfica no controle do sangramento e dequitação(1). Tem havido o uso indiscriminado de ocitócitos com a finalidade de acelerar o parto ${ }^{(7)}$. No entanto, não existem benefícios comprovados no uso rotineiro de ocitocina, mas existem efeitos colaterais, tais como a hiperestimulação uterina e o aumento da dor ${ }^{(1)}$.

Outra prática considerada rotineira no $\mathrm{CO}$ em estudo é a amniotomia. Embora existam evidências de que a amniotomia precoce possa reduzir a duração do trabalho de parto, efeitos indesejáveis podem ocorrer, tais como o incremento de desacelerações precoces dos batimentos cardíacos fetais e alterações sobre o pólo cefálico. Além dessas complicações, quanto maior a duração do parto com membranas rotas, maior o risco de infecção ovular e puerperal. Dessa forma, a rotura artificial da bolsa deve ser evitada, reservando-se seu uso para aquelas condições onde sua prática seja claramente benéfica, como é o caso de algumas distócias funcionais ${ }^{(1)}$.

A falta de registros adequados nos prontuários, também foi evidenciada em outros estudos ${ }^{(5,11,19)}$ que buscaram avaliar a assistência a esta população, revelando um problema que compromete a qualidade do serviço. O partograma, representação gráfica do trabalho, é prática importante que possibilita acompanhar a evolução da parturição, a dilatação cervical e a descida fetal, documentar, diagnosticar alterações, indicar a tomada de condutas apropriadas para a correção de possíveis desvios e evitar intervenções desnecessárias ${ }^{(1)}$. Tal resultado não se diferencia de outras instituições, como é o caso das maternidades públicas do Rio de Janeiro. Nestes locais, na maioria das vezes, quando utilizado o partograma, este é preenchido de forma incorreta, o que compromete o acompanhamento do trabalho de parto ${ }^{(19)}$.

Dentre os procedimentos imprescindíveis para a admissão/ internação da parturiente, estão a anamnese, o exame clínico e o exame obstétrico. A anamnese, mesmo no caso de 
gestantes de baixo risco, deve avaliar os antecedentes mórbidos, antecedentes obstétricos, data da última menstruação, informações sobre a movimentação fetal, além de dados referentes à evolução da gestação atual. Em relação ao exame clínico, o MS preconiza que, nas gestações de evolução normal, a avaliação clínica, ainda que sumária, deve incluir medida dos sinais vitais, avaliação das mucosas para inferir a presença ou não de anemia, a presença ou não de edema e varizes nos membros inferiores, e a ausculta cardíaca e pulmonar ${ }^{(1)}$. As condutas que envolvem a vigilância fetal, de igual forma são consideradas indispensáveis para diagnosticar o sofrimento fetal e evitar a asfixia perinatal e suas conseqüências ${ }^{(19)}$.

A baixa incidência das práticas invasivas neste estudo pode estar atrelada também à falta de registros adequados nos prontuários. Ademais, o desenvolvimento dessas práticas de modo indiscriminadas, além de aumentar a sensação de dor nas parturientes, podem representar riscos de infecção e traumas, e dificultar a deambulação e alteração na posição durante o trabalho de parto ${ }^{(1)}$.

Os achados relacionados à analgesia podem não corresponder fidedignamente à realidade, em vista de que pode ter havido o entendimento, no momento da coleta dos dados, de que a questão referia-se à anestesia local anterior à episiotomia, pois a prática de analgesia não se caracteriza como rotineira no $\mathrm{CO}$ em estudo. Existem controvérsias sobre a interferência da analgesia no progresso do trabalho de parto e na vitalidade do recém-nascido. Um estudo que buscou investigar a repercussão desta prática, evidenciou que a utilização de pequenas doses de anestésico local não influencia no trabalho de parto, em relação ao peso e Apgar do recém-nascido(20) ${ }^{(20}$ entanto, o MS recomenda a utilização de métodos não farmacológicos para o alívio da dor, por considerar que estes permitem à mulher maior controle sobre o processo parturitivo ${ }^{(1)}$.

\section{CONSIDERAÇÕES FINAIS}

O presente estudo, mediante uma abordagem quantitativa, conseguiu identificar práticas no parto de adolescentes consideradas adequadas e inadequadas, mostrando a necessidade de incentivar ainda mais a utilização de procedimentos embasados em evidência científica e inseridos dentro da proposta de humanização do parto. É necessário considerar que algumas diferenças nas práticas segundo categoria funcional podem não ter mostrado significância devido à falta de poder estatístico.

Nesta perspectiva, foi possível analisar as práticas que estão sendo desenvolvidas na atenção ao parto de adolescentes e, ao estabelecer uma correlação com a política de humanização do parto, evidenciou-se que a implementação desta proposta no contexto em estudo parece ser um grande desafio. Isto se configura como um dado preocupante, pois a unidade em estudo faz parte de uma instituição acadêmica, na qual modelos de assistência são reproduzidos. Todavia, este estudo pode contribuir para a reflexão sobre o processo de trabalho que vem sendo desenvolvido e, a partir disso, fundamentar as transformações necessárias para tornar as práticas da assistência ao parto humanizadas.

Enfim, recomenda-se que, para iniciar este processo de reflexão e transformações no âmbito da assistência à parturição, seja necessário compreender que o significado de humanizar envolve os aspectos mais subjetivos do ser humano. Para tanto, não se deve esperar apenas uma mudança na postura dos trabalhadores, mas também em todas as relações interpessoais existentes neste contexto. As condições dignas de trabalho, a valorização, a capacitação e a sensibilização dos trabalhadores da saúde, são meios de fazer com que estes se sintam humanizados e, assim, entendam a importância de humanizar.

\section{REFERÊNCIAS}

1. Ministério da Saúde (BR). Secretaria de Políticas de Saúde. Área Técnica da Saúde da Mulher. Parto, aborto e puerpério: assistência humanizada à mulher. Brasília: Ministério de Saúde; 2001.

2. Nagahama EEI, Santiago SM. Práticas de atenção ao parto e os desafios para humanização do cuidado em dois hospitais vinculados ao Sistema Único de Saúde em município da Região Sul do Brasil. Cad. Saúde Pública 2008;24(8):1859-68.

3. Spindola T, Silva LFF. Perfil epidemiológico de adolescentes atendidas no pré-natal de um hospital universitário. Esc. Anna Nery Rev. Enferm. 2009;14(1):99-107.

4. Manzini FC, Borges VTM, Parada CMGL. Avaliação da assistência ao parto em maternidade terciária do interior do Estado de São Paulo, Brasil. Rev. Bras. Saúde Mater. Infant. 2009;9(1):59-67.

5. Brasil. Agência Nacional de Vigilância Sanitária. Resolução $N^{\circ} 36 / 2008$, de 3 de junho de 2008. Dispõe o sobre Regulamento Técnico para Funcionamento dos Serviços de Atenção Obstétrica e Neonatal. 2008 Jun [citado em abr. 2009]. Disponível em: http://www.abenfosp.com.br/ mt/resolucao_36_junho_2008.pdf

6. Oliveira ZMLP, Madeira AM. Vivenciando o parto humanizado: um estudo fenomenológico sob a ótica de adolescentes. Rev. Enferm. UERJ 2002;36(2):133-40.

7. Griboski RA, Guilbem D. Mulheres e profissionais de saúde: imaginário cultural na humanização ao parto e nascimento. Texto Contexto Enferm. 2006;15(1):107-14.

8. Domingues RMM, Santos EM, Leal MC. Aspectos da satisfação das mulheres com a assistência ao parto: contribuição para o debate. Cad. Saúde Pública. 2004;20 Suppl 1:552-62.

9. Monteiro JCS, Gomes FAG, Nakamo AMS. Percepção das mulheres acerca do contato precoce e da amamentação em sala de parto. Acta Paul. Enferm. 2006;19(4):427-32.

10. Brasil. Lei no 8.069, de 13 de julho de 1990. Dispõe sobre o Estatuto da Criança e do Adolescente (ECA) e dá outras providências. 1990 Set [citado em abr. 2009]. Disponível em: http://www.planalto.gov.br/ccivil_03/leis/L8069.htm 
11. D'Orsi E, Chor D, Giffin K, Ângulo-Tuesta A, Barbosa GP, Gama AS et al. Qualidade da atenção ao parto em maternidades do Rio de Janeiro. Rev. Saúde Pública. 2005;39(4):646-54.

12. Sodré TM, Lacerda RA. O processo de trabalho na assistência ao parto em Londrina-PR. Rev. Esc. Enferm. USP 2007;41(1):82-9.

13. Mouta RJO, Pilotto DTS, Vargens OMC, Progianti JM. Relação entre posição adotada pela mulher no parto, integridade perineal e vitalidade do recém-nascido. Rev Enferm. UERJ. 2008; 16(4):472-6.

14. Santos JO, Shimo AKK. Prática rotineira da episiotomia refletindo a desigualdade de poder entre profissionais de saúde e mulheres. Esc. Anna Nery Rev. Enferm. 2008;12(4):645-50.

15. Carroli G, Belizan J. Episiotomy for vaginal birth (Cochrane Review). The Reproductive Health Issue 1. Oxford: Update Software; 2006.
16. Previatti JF, Souza KV. Episiotomia: em foco a visão das mulheres. Rev. Bras. Enferm. 2007;60(2):197-201.

17. Cecatti J, Calderón IMP. Intervenções benéficas durante o parto para a prevenção da mortalidade materna. Rev. Bras. Ginecol. Obstet. 2005;27(6):357-65.

18. Lopes MHBM, Silva MAS, Christóforo FFM, Andrade DC], Bellini NR, Cervi RC, Amaral, MCE. O uso do enteroclisma no preparo para o parto: análise de suas vantagens e desvantagens. Rev. Latino-Am. Enfermagem 2001;9(6):49-55.

19. Oliveira MIC, Dias MAB, Cunha CB, Leal MC. Qualidade da assistência ao trabalho de parto pelo Sistema Único de Saúde (RJ), 1999-2001. Rev. Saúde Pública. 2008;42(5):895-902.

20. Eberle AS, Ganem EM, Módolo NS, Amorim RB, Nakuma G, Marques CO, Castiglia YMM. Interação entre analgesia de parto e o seu resultado. Avaliação pelo peso e índice de apgar do recém-nascido. Rev. Bras. Anestesiol. 2006;56(4):343-351. 